infectious status for some discrepant samples. It is likely that 10 12 instances can be attributed to false culture readings, and 3-5 to false NAAT results. Self-limited infections were noted more frequently among younger macaques. Friable tissue was noted more frequently among older animals. Four of the five animals that were re-challenged with TV developed infection.

Conclusions The NAAT gave fewer false results, when we had the luxury of a timeline of serial samples to refer to for determining test accuracy. Similar infection rates were observed in both age cohorts. Older animals had a greater incidence of cervicovaginal irritation evidenced primarily by friability in this study, and younger animals tended to self-clear $T$. vaginalis infection faster than older animals. Finally, TV re-infection is possible in the macaque model.

Disclosure of interest statement This research was supported by NIH Contract Number HHSN266200700013C and by the Office of Research Infrastructure Programs (ORIP) of the National Institutes of Health through Grant Number P51 OD010425 Washington National Primate Research Centre. No pharmaceutical grants were received in the development of this study.

\section{P08.09 TRENDS IN CHLAMYDIA AND GONORRHOEA TESTING AND POSITIVITY IN WESTERN AUSTRALIAN WOMEN, 1998-2013}

1J Reekie*, , B Donovan, ${ }^{1} \mathrm{R}$ Guy, ${ }^{2} \mathrm{D}$ Mak, ${ }^{3} \mathrm{~S}$ Pearson, ${ }^{\mathrm{B}} \mathrm{B}$ Liu. ${ }^{1}$ The Kirby Institute, UNSW Australia; ${ }^{2}$ School of Medicine, The University of Notre Dame; ${ }^{3}$ Faculty of Pharmacy and School of Public Health, University of Sydney; ${ }^{4}$ School of Public Health and Community Medicine, UNSW Australia

\subsection{6/sextrans-2015-052270.355}

Introduction Annual genital chlamydia and gonorrhoea notifications have been rising in Australia. This study investigated changes in the patterns of chlamydia and gonorrhoea testing and positivity among women of reproductive age.

Methods A cohort of women born between 1970 and 1995 residing in Western Australia (WA) was determined from birth registrations and the current electoral roll and probabilistically linked with pathology records from one large laboratory providing services in Perth and parts of regional WA. All chlamydia and gonorrhoea tests conducted from 1998-2013 that linked to the cohort were examined.

Results There were 380,242 women included, with 99,134 (26\%) having at least one chlamydia test and 82,064 (22\%) at least one gonorrhoea test. Annually, the proportion of chlamydia tests in women aged 15-24 increased from $1.5 \%$ in 1998 to $8.7 \%$ in 2013 and among women aged $\geq 25$ from $1.1 \%$ to $4.4 \%$. Concurrent gonorrhoea testing also increased over this period from $52.7 \%$ to $81.7 \%$ of all chlamydia tests; a trend observed across all age groups. The percentage of positive chlamydia tests increased in those aged $15-24$ (5.9\% in 1998 to $8.2 \%$ in 2013) but not in those aged $\geq 25$ (3.9\% and $2.5 \%$ respectively). The proportion of positive gonorrhoea tests decreased from $1.4 \%$ to $0.4 \%$, this decrease was observed across all age groups.

Conclusion The proportion of chlamydia tests among women of reproductive age in WA increased over time and chlamydia positivity increased among women aged 15-24. Gonorrhoea positivity decreased however, this coincided with an increase in concurrent gonorrhoea testing.

Disclosure of interest statement The authors have no conflicts of interest to declare

\section{P08.10 CHLAMYDIA TRACHOMATIS INFECTION IN SAMOAN} WOMEN: PREVALENCE AND RISK FACTORS

${ }^{1} \mathrm{M}$ Walsh, ${ }^{2} \mathrm{E}$ Hope, ${ }^{3} \mathrm{~L}$ Isaia, ${ }^{1} \mathrm{~A}$ Righarts*, ${ }^{3} \mathrm{~T}$ Niupulusu, ${ }^{4} \mathrm{~V}$ Temese, ${ }^{5} \mathrm{~L}$ losefa-Siitia, ${ }^{2}$ L Auvaa, ${ }^{6} \mathrm{~A}$ Tapelu, ${ }^{7} \mathrm{M}$ Motu, ${ }^{1} \mathrm{C}$ Edwards, ${ }^{1} \mathrm{M}$ Wernick, ${ }^{8} \mathrm{~W}$ Huston, ${ }^{9} \mathrm{~T}$ Suaalii- Sauni, ${ }^{1} \mathrm{P}$ Hill. ${ }^{1}$ Centre for International Health, University of Otago, Dunedin, New Zealand; ${ }^{2}$ Faculty of Applied Science, National University of Samoa, Samoa; ${ }^{3}$ Laboratory Division, National Health Service, Samoa; ${ }^{4}$ Centre for Samoan Studies, National University of Samoa, Samoa; ${ }^{5}$ Samoa Family Health Association, Samoa; ${ }^{6}$ Samoa AIDS Foundation, Samoa; ${ }^{7}$ Samoa National Council of Churches, Samoa; ${ }^{8}$ Queensland University of Technology, Australia; ${ }^{9}$ Victoria University of Wellington, New Zealand

\subsection{6/sextrans-2015-052270.356}

Introduction Knowledge about genital Chlamydia trachomatis (CT) infection in the Pacific is limited to studies of antenatal women. We approached studying CT infection in Samoan women by using a maternal and family health focus, investigating both CT and infertility amongst women exposed to pregnancy risk.

Methods Women having unprotected intercourse aged 18-29 years were recruited from 41 Samoan villages. They were answered a behavioural questionnaire and provided a urine sample for CT testing by nucleic acid amplification. Associations between CT infection and possible risk factors were explored using logistic regression.

Results 239 women were recruited; 86 (36.0\%; weighted estimate: 41.9\%; 95\% CI: 33.4-50.5\%) were positive for CT infection. Being single (OR 1.92; 95\% CI, 1.02-3.63) and having two or more lifetime sexual partners (OR 3.02; 95\% CI, 1.197.67) were both associated with CT infection. However, a very high prevalence was still seen in those reporting only one lifetime partner $(27.6 \%)$. Participants who had a previous pregnancy were less likely to be positive (OR 0.49 ; 95\% CI, 0.27 $0.87)$. Although a slightly higher proportion of women aged 18 24 were positive than those aged 25-29, age was not significantly associated with infection.

Conclusion Whilst this sample may be considered high risk, use of barrier protection in Samoa has previously been found to be extremely uncommon and women had reported relatively few partners within the current study. Therefore, this study confirms findings from World Health Organization antenatal surveys: the prevalence of CT infection in Samoan women is likely to be very high. Studies with further assessment of the impact of CT on pelvic inflammatory disease and infertility, studies including men and strategies for sustainable control are needed.

Disclosure of interest statement This study was funded by The New Zealand Aid Programme and The University of Otago. The Secretariat of the Pacific Community provided the Chlamydia test kits for free. No pharmaceutical grants were received in the development of this study.

\section{P08.11 CHLAMYDIA TRACHOMATIS INCIDENCE FROM SELF- REPORTS AND SEROLOGY BY AGE-PERIOD, SEX AND PARTNER NUMBERS IN A BIRTH COHORT}

${ }^{1}$ AA Righarts*, ${ }^{1} \mathrm{NP}$ Dickson, ${ }^{2} \mathrm{~J}$ Morgan, ${ }^{3} \mathrm{P}$ Horner, ${ }^{4} \mathrm{M}$ McClure, ${ }^{4} \mathrm{GS}$ Wills. ${ }^{1}$ Department of Preventive and Social Medicine, University of Otago, Dunedin, New Zealand; ${ }^{2}$ Sexual Health Clinic, Waikato Hospital, Hamilton, New Zealand; ${ }^{3}$ School of Social of Social and Community Medicine, University of Bristol, Bristol, UK; ${ }^{4}$ Jefferiss Trust Laboratories, WrightFleming Institute, Imperial College London, London, UK

\section{$10.1136 /$ sextrans-2015-052270.357}

Background Better understanding of the epidemiology of Chlamydia trachomatis (CT) would assist in prevention and control, 